\title{
MANAJEMEN PENGENDALIAN RISIKO PADA BAGIAN PRODUKSI DI PABRIK GULA KEDAWOENG KABUPATEN PASURUAN TAHUN 2020
}

Nisrina Nuha Sholiha*, Hadi Suryono, Marlik

Jurusan Kesehatan Lingkungan Poltekkes Kemenkes Surabaya

*Email korespondensi: ikanisrina1@gmail.com

\begin{abstract}
ABSTRAK
Pabrik Gula Kedawoeng Pasuruan adalah agrobisnis perkebunan dengan produk utama core bussines gula. Penggunaan mesin dan peralatan kerja dalam aktivitas produksi ini dapat menyebabkan adanya kebisingan pada kegiatan produksi yang dihasilkan dari pengoperasian mesin vakum pan dan gerinda berdasarkan data sekunder. Pengelolaan manajemen risiko kesehatan dan keselamatan kerja yang baik mengacu pada pengendalian risiko perlu dilakukan untuk mencapai zero accident.

Penelitian ini bersifat deskriptif kualitatif. Pengumpulan data dilakukan dengan mengolah data sekunder di Pabrik Gula Kedawoeng tahun 2020 meliputi pengukuran lingkungan fisik kerja. Objek penelitian sebanyak 179 orang pekerja area produksi. Data dianalisis menggunakan matriks AS / NZ 4360: 2004.

Hasil penelitian berupa analisis dan penilaian iklim kerja di 5 area produksi terdapat 4 (empat) risiko dengan kategori rendah (Low) dan 1 (satu) risiko dengan kategori tinggi (High), pada intensitas pencahayaan terdapat 2 (dua) risiko berkategori rendah (Low) dan 3 (tiga) risiko berkategori sedang (Medium). Penilaian kebisingan kegiatan Maintenance terdapat 2 (dua) risiko berkategori rendah (Low) dan 3 (tiga) risiko berkategori sedang (Medium), dan pada tingkat kebisingan kegiatan produksi terdapat 1 (satu) risiko berkategori sedang (Medium) dan 4 (risiko) berkategori sangat tinggi (Very High).

Perlu adanya pengendalian risiko pada area produksi dengan risiko kategori tinggi (High). Salah satunya dengan memperbaiki manajemen P2K3 dalam hal mengurangi tingkat risiko kecelakaan kerja yang ada di pabrik tersebut.
\end{abstract}

Kata kunci: Identifikasi, analisis, penilaian, dan pengendalian risiko

\section{PENDAHULUAN}

Perkembangan industri di Indonesia sekarang ini berlangsung sangat pesat. Proses industrialisasi makin cepat dengan berdirinya perusahaan dan tempat kerja yang beraneka ragam diiringi adanya risiko bahaya yang lebih besar dan beraneka ragam karena adanya peralihan teknologi dimana penggunaan mesin dan peralatan kerja yang semakin kompleks untuk mendukung proses produksi dapat menimbulkan masalah kesehatan dan keselamatan kerja (Ekfan, Susanto, 2017).

Keselamatan dan Kesehatan Kerja (K3) adalah suatu program yang dibuat bagi pekerja maupun pengusaha sebagai upaya pencegahan (preventif) timbulnya kecelakaan kerja dan penyakit akibat hubungan kerja dalam lingkungan kerja dengan cara mengenali hal-hal yang berpotensi menimbulkan kecelakaan kerja dan penyakit akibat hubungan kerja, serta tindakan antisipatif bila terjadi hal demikian (Mulyani, 2016).

Penerapan Keselamatan dan Kesehatan Kerja (K3) yang dilakukan salah satunya ialah perusahaan wajib menjamin keselamatan dan kesehatan di lingkungan perusahaan terutama tenaga kerja. Hal ini bertujuan untuk kenyamanan pekerja dan meningkatkan produktifitas kerja (Undang-undang Nomor 1 Tahun 1970). Syarat K3 lingkungan kerja yang aman sebagaimana dimaksud dalam pemenaker RI No. 5 Tahun 2018 adalah pengendalian faktor fisik agar berada di Nilai Ambang Batas yang diizinkan oleh lingkungan kerja yang keberadaanya dapat mempengaruhi K3 tenaga kerja (Mentari, Imran, and Raharjo, 2018).

World Health Organization (WHO, 2016) menyebutkan 45\% penduduk dunia adalah tenaga kerja, 58\%-nya merupakan tenaga kerja berusia lenih dari 10 tahun. Diperkirakan dari jumlah 
tenaga kerja di atas, sebesar $35 \%$ sampai $50 \%$ pekerja di dunia terpajan bahaya fisik, kimia, biologi, dan juga bekerja dalam beban kerja fisik dan ergonomi yang melebihi kapasitasnya termasuk pula beban kerja psikologis. Berdasarkan statistik International Labour Office (ILO), 120 juta kecelakaan kerja terjadi setiap tahunnya di tempat kerja di seluruh dunia (Winarto, dkk, 2016)

PT. Perkebunan Nusantara XI (Persero) PG Kedawoeng atau lebih dikenal Pabrik Gula Kedawoeng adalah Badan Usaha Milik Negara (BUMN) agrobisnis perkebunan dengan produk utama core bussines gula. Berlokasi di Kabupaten Pasuruan. Perusahaan ini bahkan satu satunya BUMN yang mengusahakan komoditas tunggal yakni gula, dengan kontribusi sekitar $16-18 \%$ terhadap produk nasional. Sebagian besar bahan baku berasal dari tebu rakyat yang diperoleh dari petani lokal melalui kemitraan dengan pabrik gula. Pabrik Gula Kedawoeng memiliki beberapa 5 unit stasiun proses produksi yaitu stasiun penggilingan, stasiun pemurnian, stasiun penguapan, stasiun pemasakan, dan stasiun pemutaran.
Dari hasil survey pendahuluan dengan menggunakan data sekunder di Pabrik Gula Kedawoeng tahun 2020, didapatkan data kejadian kecelakaan kerja di dalam Pabrik Kedawoeng pada tahun 2017 sebanyak 6 kejadian. Kecelakaan kerja pada tahun 2018 sebanyak 2 kejadian, dan kecelakaan lalu lintas tahun 2019 sebanyak 2 kejadian. Kecelakaan kerja yang sering terjadi disebabkan oleh tindakan manusia yang tidak aman (human error). Tujuan penelitian ini mengidentifikasi, menilai, menganalisis dan mengendalikan risiko ditinjau dari faktor lingkungan fisik kerja meliputi iklim kerja, pencahayaan, dan kebisingan.

\section{METODE PENELITIAN}

Penelitian ini menggunakan pendekatan deskriptif kualitatif, dengan desain penelitian studi kasus (case study). Objek penelitian sebanyak 179 orang pekerja yang bekerja di area produksi. Data dianalisis menggunakan matriks AS / NZ 4360: 2004.

\section{HASIL DAN PEMBAHASAN}

Tabel 1

DATA HASIL PENGUKURAN IKLIM KERJA AREA PRODUKSI PG KEDAWOENG

\begin{tabular}{|c|c|c|c|c|c|}
\hline No & Lokasi Pengukuran & $\begin{array}{l}\text { ISBB } \\
\left({ }^{\circ} \mathrm{C}\right)\end{array}$ & $\begin{array}{c}\text { Consequences } \\
\text { (C) }\end{array}$ & $\begin{array}{l}\text { Likelihood } \\
\text { (L) }\end{array}$ & Risk Rating \\
\hline 1. & Stasiun Pengolahan & 28,7 & $\begin{array}{c}1 \\
\text { Insignification }\end{array}$ & $\begin{array}{c}1 \\
\text { Rare }\end{array}$ & $\begin{array}{c}1 \\
\text { Low }\end{array}$ \\
\hline 2. & Stasiun Penguapan & 28,5 & $\begin{array}{c}2 \\
\text { Minor }\end{array}$ & $\begin{array}{c}2 \\
\text { Likely }\end{array}$ & $\begin{array}{c}4 \\
\text { Low }\end{array}$ \\
\hline 3. & Stasiun Pemutaran & 28,3 & $\begin{array}{c}2 \\
\text { Minor }\end{array}$ & $\begin{array}{c}2 \\
\text { Likely }\end{array}$ & $\begin{array}{c}4 \\
\text { Low }\end{array}$ \\
\hline 4. & Stasiun Pemurnian & 28,4 & $\begin{array}{c}2 \\
\text { Minor }\end{array}$ & $\begin{array}{c}2 \\
\text { Likely }\end{array}$ & $\begin{array}{c}4 \\
\text { Low } \\
\end{array}$ \\
\hline 5. & $\begin{array}{l}\text { Stasiun } \\
\text { Penggilingan }\end{array}$ & 28,1 & $\begin{array}{c}3 \\
\text { Moderate }\end{array}$ & $\begin{array}{c}5 \\
\text { Almost } \\
\text { Certain }\end{array}$ & $\begin{array}{c}15 \\
\text { High }\end{array}$ \\
\hline
\end{tabular}

Hasil penelitian menggunakan matriks AS/NZ 3406 : 2004 menunjukkan data pengukuran iklim kerja risiko tertinggi berada di stasiun penggilingan. Hasil penelitian juga selaras dengan penelitian (Fatimah and Indrawati, 2019) yang berjudul Masa
Kerja, Beban Kerja, Konsumsi Air Minum dan Status Kesehatan dengan Regangan Panas pada Pekerja Area Kerja menyatakan bahwa terdapat hubungan iklim kerja dengan terjadinya gangguan kesehatan kesehatan pada pekerja apabila pekerja terpapar oleh tekanan 
panas melebihi 8 jam per hari atau 40 jam seminggu. Dampak fisik yang ditimbulkan mulai dari keluhan ringan seperti ruam pada kulit atau pingsan.

Pengendalian iklim kerja salah satunya dengan pekerja yang bekerja pada lingkungan kerja panas dianjurkan untuk minum 1 gelas air $(250 \mathrm{ml})$ setiap 30 menit. Hal ini bertujuan untuk menjaga tubuh dari dehidrasi akibat banyaknya cairan tubuh yang hilang akibat aktivitas fisik yang dilakukan dan paparan panas yang dihadapi.

Tabel 2

DATA HASIL PENGUKURAN PENCAHAYAAN AREA PRODUKSI PG KEDAWOENG

\begin{tabular}{|c|c|c|c|}
\hline No & Lokasi Pengukuran & $\begin{array}{c}\text { Pencaha- } \\
\text { yaan } \\
\text { (Lux) }\end{array}$ & $\begin{array}{c}\text { Consequences } \\
\text { (C) }\end{array}$ \\
\hline \multicolumn{2}{|c|}{ 1. Stasiun Pengolahan } & 247 & $\begin{array}{c}1 \\
\text { Insignification }\end{array}$ \\
\hline 2. & Stasiun Penguapan & 202 & $\begin{array}{c}4 \\
\text { Medium } \\
\end{array}$ \\
\hline 3. & Stasiun Pemutaran & 155 & $\begin{array}{c}3 \\
\text { Moderate }\end{array}$ \\
\hline 4. & Stasiun Pemurnian & 256 & $\begin{array}{c}8 \\
\text { Medium } \\
\end{array}$ \\
\hline 5. & $\begin{array}{l}\text { Stasiun } \\
\text { Penggilingan }\end{array}$ & 209 & $\begin{array}{c}8 \\
\text { Medium } \\
\end{array}$ \\
\hline & $\begin{array}{l}\text { Hasil penelitian } \\
\text { ks AS/NZ } 3406: 2004 \\
\text { pengukuran penca } \\
\text { tertinggi berada } \\
\text { taran. Hasil penelitia } \\
\text { an penelitian (Man } \\
\text { berjudul evaluasi } \\
\text { ingan, temperatur, } \\
\text { line } 3 \mathrm{pt} \text { south } \\
\text { latakan bahwa terda } \\
\text { isi fisik lingkungan ker } \\
\text { enuhi standar akan } \\
\text { isi dan produktivitas } \\
\text { bekerja pada area prc }\end{array}$ & $\begin{array}{l}\text { menggunakan } \\
\text { menunjukkan } \\
\text { hayaan kerja } \\
\text { di stasiun } \\
\text { juga selaras } \\
\text { ullang, 2015) } \\
\text { pencahayaan, } \\
\text { dan getaran } \\
\text { pasific viscose } \\
\text { pat hubungan } \\
\text { ja yang belum } \\
\text { mempengaruhi } \\
\text { tenaga kerja } \\
\text { oduksi. Banyak }\end{array}$ & $\begin{array}{l}\text { Langkah-langkah dalam Pengendalian } \\
\text { pencahayaan salah satunya dengan } \\
\text { emodifikasi sistem penerangan yang } \\
\text { sudah ada dengan merubah posisi } \\
\text { lampu, mengganti jenis lampu maupun } \\
\text { menambah jumlah lampu. } \\
\text { Bila menggunakan penerangan } \\
\text { alami harus diperhatikan agar jalan } \\
\text { masuknya sinar tidak terhalang. Selain } \\
\text { itu menjaga kebersihan dinding, langit- } \\
\text { langit, lantai, lampu dan perangkatnya. } \\
\text { Perawatan harus dilakukan secara rutin } \\
\text { karena kotoran dan debu dapat } \\
\text { berpotensi mengurangi intensitas } \\
\text { pencahayaan hingga } 35 \% \text {. }\end{array}$ \\
\hline
\end{tabular}
obyek kerja beserta benda atau alat dan kondisi di sekitar yang perlu dilihat oleh tenaga kerja. 
Tabel 3

DATA HASIL PENGUKURAN KEBISINGAN MAINTENANCE AREA PRODUKSI PG KEDAWOENG

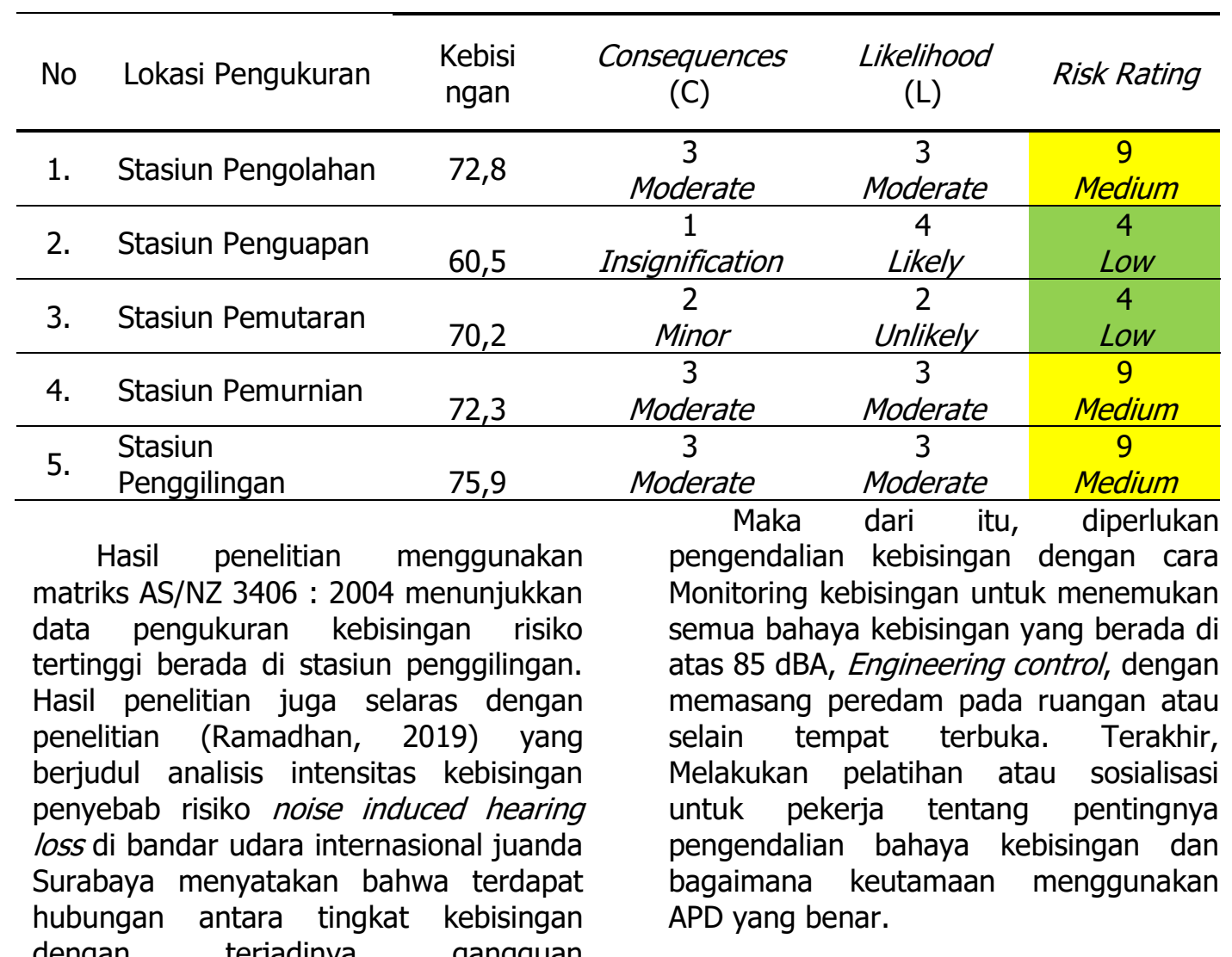

dengan terjadinya gangguan

pendengaran apabila intensitas rata-rata yang masih bisa diterima tenaga kerja melebihi 8 jam sehari atau 40 jam seminggu.

Tabel 4

DATA HASIL PENGUKURAN KEBISINGAN KEGIATAN AREA PRODUKSI PG KEDAWOENG

\begin{tabular}{|c|c|c|c|c|c|}
\hline No & Lokasi Pengukuran & $\begin{array}{c}\text { Kebisi } \\
\text { ngan }\end{array}$ & $\begin{array}{c}\text { Consequences } \\
\text { (C) }\end{array}$ & $\begin{array}{l}\text { Likelihood } \\
\text { (L) }\end{array}$ & Risk Rating \\
\hline 1. & Sta. Penggilingan & 79 & $\begin{array}{c}5 \\
\text { Catastrophic }\end{array}$ & $\begin{array}{c}5 \\
\text { Almost }\end{array}$ & $\begin{array}{c}25 \\
\text { Very high }\end{array}$ \\
\hline 2. & Stasiun Pemurnian & 87 & $\begin{array}{c}5 \\
\text { Catastrophic }\end{array}$ & $\begin{array}{c}5 \\
\text { Almost }\end{array}$ & $\begin{array}{c}25 \\
\text { Very high }\end{array}$ \\
\hline 3. & Stasiun Penguapan & 88 & $\begin{array}{c}5 \\
\text { Catastrophic }\end{array}$ & $\begin{array}{c}5 \\
\text { Almost }\end{array}$ & $\begin{array}{c}25 \\
\text { Very high }\end{array}$ \\
\hline 4. & Stasiun Pemasakan & 91 & $\begin{array}{c}5 \\
\text { Catastrophic }\end{array}$ & $\begin{array}{c}5 \\
\text { Almost }\end{array}$ & $\begin{array}{c}25 \\
\text { Very high }\end{array}$ \\
\hline 5. & Stasiun Pemutaran & 94 & $\begin{array}{c}3 \\
\text { Moderate }\end{array}$ & $\begin{array}{c}2 \\
\text { Unlikely }\end{array}$ & $\begin{array}{c}6 \\
\text { Medium }\end{array}$ \\
\hline
\end{tabular}


Hasil penelitian menggunakan matriks AS/NZ 3406 : 2004 menunjukkan data pengukuran kebisingan kegiatan produksi risiko tertinggi berada di stasiun pemutaran. Hasil penelitian juga selaras dengan penelitian (Ramadhan, 2019) yang berjudul analisis intensitas kebisingan penyebab risiko noise induced hearing loss di Bandar Udara Internasional Juanda Surabaya menyatakan bahwa terdapat hubungan antara tingkat kebisingan dengan terjadinya gangguan pendengaran apabila intensitas rata-rata yang masih bisa ditahan atau diterima tenaga kerja melebihi 8 jam sehari atau 40 jam seminggu.

Diperlukan pengendalian kebisingan dengan cara monitoring kebisingan untuk menemukan semua bahaya kebisingan yang berada di atas $85 \mathrm{dBA}$, Engineering control, dengan memasang peredam pada ruangan atau selain tempat terbuka. Upaya yang dilakukan melalui pelatihan atau sosialisasi untuk pekerja tentang pentingnya pengendalian bahaya kebisingan dan bagaimana keutamaan menggunakan APD yang benar.

\section{KESIMPULAN}

Terdapat potensi risiko lingkungan fisik kerja meliputi tingkat kebisingan kegiatan area produksi di Pabrik gula Kedawoeng Pasuruan berdasarkan hasil identifikasi, analisis, penilaian dan pengendalian lingkungan kerja.

\section{SARAN}

Bagi perusahaan khususnya Pabrik Gula Kedawoeng : memperbaiki sistem manajemen P2K3 dalam hal mengurangi tingkat risiko kecelakaan kerja yang ada di pabrik tersebut dan melakukan tinjauan ulang pada hasil penelitian yang dilakukan penulis.

\section{DAFTAR PUSTAKA}

Ekfan Susanto. 2017. "Pengaruh Penerapan Program Keselamatan Dan Kesehatan Kerja Terhadap Produktivitas Karyawan Di PT. Nestle Indonesia Pabrik Panjang Bandar Lampung ( Tesis ) Oleh Ekfan Susanto Program Pascasarjana Magister Manajemen," 118.
Mulyani, Siti. 2016. "Dengan Menggunakan Metode Domino Pada Pembangunan Proyek Apartemen Grand Taman Melati MargondaDepok Using Domino Method Of Development Apartment Project Of Grand Taman Melati MargondaDepok." Jurusan Teknik Sipil TUGAS AKHI: 1-7.

Mentari, Ajeng Putri, Rani Aulia Imran, And Kuwat Raharjo. 2018. "Evaluasi Penerapan K3 Lingkungan Kerja Faktor Fisika Pada Proses Produksi Karet Di PT. PN IX Krumput." Prosiding Seminar Nasional K3 SHEA, UNS, Surakarta, No. November.

Winarto, Sigit, Hanifa Maher Denny, And Bina Kurniawan. 2016. "Studi Kasus Kecelakaan Kerja Pada Pekerja Pengeboran Migas Seismic Survey PT. X Di Papua Barat." Jurnal Promosi Kesehatan Indonesia 11 (1): 51. Https://Doi.Org/10.14710/Jpki.11.1. 51-65.

Fatimah, Siti, And Fitri Indrawati. 2019. "Masa Kerja, Beban Kerja, Konsumsi Air Minum Dan Status Kesehatan Dengan Regangan Panas Pada Pekerja Area Kerja." Higeia Journal Of Public Health Research And Development 3 (4): 524-33.

Manullang, Anindyaka Lamhot Edward. 2015. "Evaluasi Pencahayaan, Kebisingan, Temperatur, Dan Getaran Pada Line 3 Pt South Pasific Viscose." Evaluasi Pencahayaan, Kebisingan, Temperatur, Dan Getaran Pada Line 3 Pt South Pasific Viscose 4 (3): 112.

Ramadhan, Ario. 2019. "Analisis Intensitas Kebisingan Penyebab Risiko Noise Induced Hearing Loss Di Bandar Udara Internasional Juanda Surabaya Analysis Of Noise Intensity Causing Noise Induced Hearing Loss Pendahuluan Bandara Internasional Juanda Surabaya , Usaha NIHL ). Para P." Journal of Industrial Hygiene And Occupational Health 3 (2): 166-73. 